\title{
Systematic Review of Prevalence of Endometriosis among Indigenous Africans
}

\author{
Gichuhi J. Wanyoike ${ }^{1}$, Rafique Parkar ${ }^{2}$, Ndegwa S. Wanjiru ${ }^{3}$ \\ ${ }^{1}$ Department of Obstetric \& Gynaecologist, University of Nairobi, Nairobi, Kenya \\ ${ }^{2}$ University of Cape Town, Cape Town, South Africa \\ ${ }^{3}$ Step to Fertility Foundation, Nairobi, Kenya \\ Email: drjoewanyoikeyahoo.co.uk
}

How to cite this paper: Wanyoike, G.J., Parkar, R. and Wanjiru, N.S. (2017) Systematic Review of Prevalence of Endometriosis among Indigenous Africans. Open Journal of Obstetrics and Gynecology, 7, 835845 .

https://doi.org/10.4236/ojog.2017.78084

Received: July 9, 2017

Accepted: July 30, 2017

Published: August 2, 2017

Copyright $\odot 2017$ by authors and Scientific Research Publishing Inc. This work is licensed under the Creative Commons Attribution International License (CC BY 4.0).

http://creativecommons.org/licenses/by/4.0/

\begin{abstract}
Introduction: Although the prevalence of endometriosis is to a certain extent documented in women living in high resource countries, its prevalence in black Africa is unknown. Since the current view is that endometriosis hardly affects indigenous Africans, we aim to provide a systematic review of prevalence of endometriosis among the indigenous Africans. Objective: To determine the prevalence and clinical presentation of endometriosis in the indigenous African women. Methodology: A systematic literature search was carried out for relevant articles on all citations on PubMed, based on the key words "Endometriosis" and "Africa". An additional search was done on African journal Online. Outcome Measures: The primary outcome measure was the prevalence of endometriosis among indigenous Africans. Results: Out of 58 identified paper's, only 4 were eligible for the systematic review. The prevalence of endometriosis was 4.3\% (Osefo et al. [1] and 8.2\% (Ekwempu et al. [2]) in the laparotomy and hysterectomy specimen respectively. In the paper by Fawole et al. [3], where endometriosis was diagnosed on the basis of laparoscopic visualization alone without histological confirmation, the prevalence was $48.1 \%$. Somigliana et al. [4] estimated endometriosis to be $0.2 \%$ based on clinical history, clinical examination and imaging, without surgical procedure to confirm this estimation. Due to differences in study populations, methodology and diagnostic criteria, it was not possible to have pooled prevalence of endometriosis. Conclusion: Although existing evidence suggests that the prevalence of endometriosis in indigenous Africans is $0.2 \%-48.1 \%$, the study analyzed had limitations. Prospective multi-centered studies with laparoscopic diagnosis and histological confirmation of endometriosis are required to establish the prevalence of endometriosis among the general population in the indigenous Africans. Endometriosis in Africa needs to receive more research attention. This paper is expected to stimulate and sensitize the clinicians and researchers in Africa about this condition.
\end{abstract}




\section{Keywords}

Endometriosis, Indigenous African, Prevalence, Laparoscopy

\section{Introduction}

Endometriosis, described, as the presence of endometrial tissue outside the uterine cavity, is a perplexing disease with a protean clinical presentation and pathology, and is associated with chronic pelvic pain and infertility, with a significant influence on the quality of life and health cost financial implication [5]. The estimated prevalence of endometriosis among in the women of reproductive age is between $2 \%$ and $10 \%$ [6]. Chronic pelvic pain and dyspareunia are two clinical presentation of endometriosis with a major impact on physical and mental constituents of quality of life [7]. The onset of symptoms of the endometriosis and its surgical diagnosis has a diagnostic delay of 6.7 years [8]. Endometriosis is a true chronic disease with a significant impairment of quality of life due to endometriosis-associated symptoms (chronic pelvic pain, dysmenorrhoe, dyspareunia and infertility) even when the management of the disease is in a tertiary centre [7]. Endometriosis is connected to discomfort/pain, anxiety/depression and social dysfunction, which affect health related quality of life. Endometriosis treatments cost has an economic burden that is comparative to that of managing chronic disease such as rheumatoid arthritis, crohns disease and diabetes mellitus [9].

In women afflicted with endometriosis, the physical HRQoL is remarkably reduced when compared with women with no endometriosis with similar symptoms; due to reduced effectiveness in work there is a loss of $10.8 \mathrm{hrs}$ per week in each of the women afflicted with endometriosis [8]. Poor yield in work was expressed into remarkable costs per woman/week from US \$4 in Nigeria to US $\$ 456$ in Italy [8].

There is limited literature on the prevalence of endometriosis among the Africans [10], probably because diagnostic laparoscopy, which is the gold standard for the diagnosis of endometriosis, is hardly executed in women with infertility and/or chronic pelvic pain. [11]. Documentation of an increased prevalence of endometriosis in Asian women in comparative to that of the Caucasian women reflects that racial predisposition may exist in the endometriosis presentation [12]. Genetic, environmental and/or the origin of endometriosis may contribute to racial differences Observed.

In the United States of America (USA), Shade et al. 2012 [13], in his literature review on the endometriosis, he found only 2 papers dedicated to the African American and the endometriosis; both papers were write by Chatman in 1975 \& 1976. Chatman 1976 [14], in the African American women who underwent diagnostic laparoscopy, he found an incidence of endometriosis to be $22.7 \%$. Chatman 1976 [14], postulated that the incidence of endometriosis was associated to the social economic status rather than the racial factor. Although, in 
indigenous African woman endometriosis is considered to be rare [10], it is a frequent etiology of gynaecological morbidity and major surgery, related to long hospitalization among African-American women in the USA [15].

Paradoxically, in African American and Indigenous African the clinical presentation and anatomical location of endometriosis is marked by a more predilection for endometriosis attachment to the uterus and atypical endometriosis than in any other races, without a rationale explanation [10] [13]. Cervical endometriosis and endometrial related-ascites appears to be a more common manifestation of endometriosis in African women than in the Caucasian women [10] [16] [17]. Genetically, the African-America and Indigenous African women are not necessarily similar, given the known genetic admixture of the African American [18].

Epidemiological characteristics that insulate against the development of endometriosis like early age at first pregnancy, multiparity, prolonged breastfeeding and a high incidence of pelvic inflammatory disease associated with closure or dysfunction of the fallopian tubes could explain the presumed low prevalence of endometriosis in African women [10] [14] [19]. In that context, it can be expected that the incidence of endometriosis will increase in African with late age of first pregnancy, few children and hence less breastfeeding and therefore higher number of menstrual cycles with increase in the opportunity for retrograde menstruation when the Fallopian tubes are open. However, the true prevalence of endometriosis is unknown in Africa because of a lack of laparoscopic diagnostic facilities. Conclusive diagnosis of endometriosis can only made by laparoscopic visual inspection with a confirmation by histology, and these can classified as peritoneal disease, ovarian endometriotic cysts (endometriomas), or deep infiltrating endometriosis (DIE) or as combination of these features [20]. Inadequate laparoscopic facilities \& infrastructure, gynecological training and lack of awareness of the disease among the African gynaecologists contribute to the underestimation of the prevalence of the endometriosis in Africa [10].

To the best of our knowledge, there has not been an effort to systematically assess the prevalence of endometriosis in indigenous Africans. The overall aim of this study is present systematic review of the prevalence of endometriosis indigenous Africans.

Objective: To determine the prevalence and clinical presentation of endometriosis in indigenous African women.

\section{Methods}

We performed a systematic literature search using the PubMed electronic database with the key words "endometriosis" and "Africa" in different combinations on 31 October 2014, without specified date or language restrictions. Further search was done in Africa Journal online. A pair of two authors (Gichuhi, Ndegwa) independently assed every study selected. We primarily looked for papers that were published in full text and that addressed the research question at hand as primary outcome (i.e. the prevalence of endometriosis among indigenous Africans). 
Therefore, we excluded manuscripts that did not contain empirical quantitative results, such as a letter to the editor, brief reports, case studies, quantitative design, opinion experts etc. In addition, we reviewed the reference lists of all selected articles in order to identify additional relevant papers. For each selected study, we extracted the following data: study location, patient selection, sample size, diagnostic method, and overall prevalence of endometriosis. Data extraction was performed independently for each article by two co-authors, as mentioned above.

\section{Results}

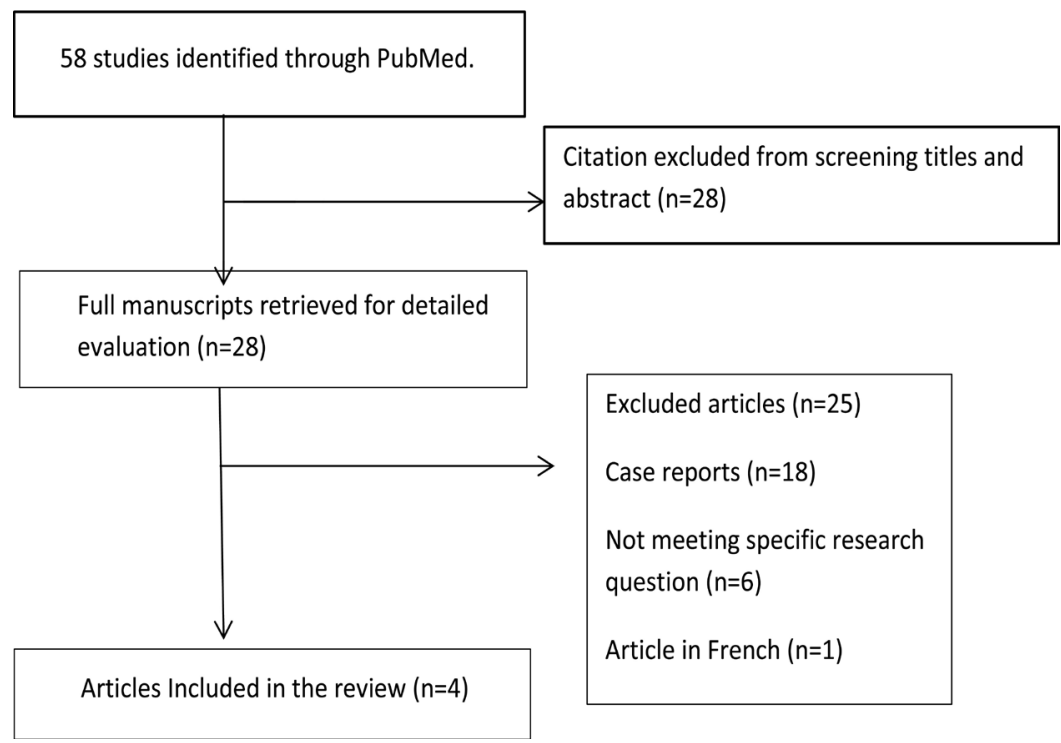

Figure 1. The process of literature identification for all citations.

As shown in Figure 1, only 4 out of 58 studies could be included in our review.

Include subjects were women $(\mathrm{n}=2482)$ with general gynecological conditions. The studies included were Ekwempu et al. 1978, Osefo et al. 1989, Fawole et al. 2015, Somiglina et al. 2012.

Table 1. Osefo et al. 1989 [1]: Types of operations and sites of endometriosis.

$\begin{array}{cc}\text { Total number of operations } & 5995 \\ \text { Minor operations } & 4416 \\ \text { Endometriosis ext. (Umbilicus) } & 6 \\ \text { (Abdominal Scar) } & \\ \text { Major operations } & 1382 \\ \text { Endometriosis } & 59 \\ \text { Adenomyosis } & 51 \\ \text { Endometriosis Externa } & 8 \\ \text { Pouch of Douglas } & 5 \\ \text { Ovary fallopian tube and uterine cornu } & 3 \\ \text { Total, external (14) and adenomyosis (51) } & \underline{65}\end{array}$


Osefo et al. found the prevalence of endometriosis in major surgery to be $4.3 \%$ (However, this was a combination of both endometriosis and adenomyosis) (Table 1).

Table 2. Ekwempu et al. [2]: Histological Finding of Endometriosis on Uterine Specimen after Hysterectomy.

\begin{tabular}{cc}
\hline Total number of Hysterectomy specimen & 329 \\
Histological confirmed Adenomyosis & 20 \\
Histological confirmed Endometriosis & 5 \\
Both Histological confirmed endometriosis and Adenomyosis & 2 \\
\hline
\end{tabular}

Prevalence of Endometriosis 8.2\% (This was inclusive of both Adenomyosis and Endometriosis) (Table 2).

Table 3. Somigliana et al. 2012 [4]; Definite diagnoses in the non-pregnant women of reproductive with symptoms suggestive of endometriosis Age $n=351$ ).

\begin{tabular}{|c|c|}
\hline Diagnosis & Number $(0 \%)$ \\
\hline \multicolumn{2}{|l|}{ Symptoms suggestive for endometriosis $(n=248)$} \\
\hline Chronic pelvic Inflammatory disease (PID) & $73(21 \%)$ \\
\hline Acute PID & $11(3 \%)$ \\
\hline Dysfunctional metrorrhagia & $23(7 \%)$ \\
\hline Unexplained infertility & $22(6 \%)$ \\
\hline Fibroids & $21(6 \%)$ \\
\hline Ovarian non-endometriotic cyst & $7(2 \%)$ \\
\hline Genital malformation & $3(1 \%)$ \\
\hline Polycystic Ovarian Syndrome (PCOS) & $3(1 \%)$ \\
\hline Other gynecological disorders & $3(1 \%)$ \\
\hline Normal genital organs (symptoms unexplained) & $29(8 \%)$ \\
\hline Non-gynecological disorders & $53(15 \%)$ \\
\hline \multicolumn{2}{|l|}{ Other symptoms $(n=103)$} \\
\hline Genital prolapse & $26(7 \%)$ \\
\hline Vulvo-vaginitis & $18(5 \%)$ \\
\hline Batholinitis & $3(1 \%)$ \\
\hline Other gynecological disorders & $7(2 \%)$ \\
\hline Normal genital organs (symptoms unexplained) & $24(7 \%)$ \\
\hline Non-gynecological disorders & $25(7 \%$ \\
\hline
\end{tabular}

Percentages refer to the total number of woman.

Endometriosis was only found in one case. However, Somigliana et al. did not use laparoscopy as a diagnostic tool (Table 3). 
Table 4. Fawole.A.O. et al. [3] -Bivariate analysis of associations between endometriosis and participant characteristics.

\begin{tabular}{|c|c|c|c|}
\hline Characteristic & $\begin{array}{c}\text { Endometriosis } \\
\text { present }\end{array}$ & $\begin{array}{c}\text { Odds ratio } \\
(95 \% \mathrm{CI})\end{array}$ & $P$ value \\
\hline \multicolumn{4}{|l|}{ Early menarche } \\
\hline Yes $(n=85)$ & $40(47.1)$ & $0.96(0.55-1.69)$ & 0.886 \\
\hline No $(n=152)$ & $73(48.0)$ & Ref. & - \\
\hline \multicolumn{4}{|c|}{ Previous spontaneous abortion } \\
\hline Yes $(n=42)$ & $19(45.2)$ & $0.87(0.42-1.78)$ & 0.681 \\
\hline No $(n=197)$ & $71(53.0)$ & Ref. & - \\
\hline \multicolumn{4}{|c|}{ Previous induced abortion } \\
\hline Yes $(n=105)$ & $44(41.9)$ & $0.64(0.38-1.07)$ & 0.089 \\
\hline No $(n=134)$ & $71(53.0)$ & Ref. & - \\
\hline \multicolumn{4}{|l|}{ Menorrhagia } \\
\hline Yes $(n=47)$ & $24(51.1)$ & $1.16(1.07)$ & 0.652 \\
\hline No $(n=192)$ & $91(47.4)$ & Ref. & - \\
\hline \multicolumn{4}{|l|}{ Dysmenorrhea } \\
\hline Yes $(n=171)$ & $90(52.6)$ & $1.01(1.07-3.04)$ & 0.027 \\
\hline No $(n=68)$ & $25(36.8)$ & Ref. & - \\
\hline \multicolumn{4}{|c|}{ Analgesic prescription for Dysmenorrhea } \\
\hline Yes $(\mathrm{n}=51)$ & $34(66.7)$ & $2.29(1.15-4.52)$ & 0.017 \\
\hline No $(n=120)$ & $56(46.7)$ & Ref. & - \\
\hline \multicolumn{4}{|c|}{ Self Medication for dysmenorrhea } \\
\hline Yes $(n=73)$ & $40(54.8)$ & $1.16(0.63-2.14)$ & 0.625 \\
\hline No $(n=98)$ & $50(51.0)$ & Ref & - \\
\hline \multicolumn{4}{|c|}{ Having had to limit activities because of dysmenorrhea } \\
\hline Yes $(n=52)$ & $34(65.4)$ & $2.13(1.08-4.18)$ & 0.002 \\
\hline No $(n=119)$ & $56(47.1)$ & Ref. & - \\
\hline \multicolumn{4}{|c|}{ Having had to lie down because of dysmenorrhea } \\
\hline Yes $(n=86)$ & $54(62.8)$ & $2.30(1.24-4.24)$ & 0.008 \\
\hline No $(\mathrm{n}=85)$ & $36(42.4)$ & Ref. & - \\
\hline
\end{tabular}

Abbreviations: CI, confidence interval. ${ }^{a}$ Values are given as number (percentage). ${ }^{\text {b }}$ when aged $<13$ years.

In this study by Fawole et al., $48.1 \%$ of women undergoing laparoscopy for gynecological conditions had visually diagnosed endometriosis without histological confirmation. Women with endometriosis more commonly reported dysmenorrhea and pelvic pain.

The prevalence of endometriosis varied in different studies as indicated in Table $4 \&$ Table 5. The intervention used to determine and diagnose endometriosis was different (Ekwempu et al.-Hysterectomy with histological confirmation, Osefo et al.- Laparotomy with histological confirmation, Somigliana et al. 2012-2012 - clinical history/clinical findings and investigation, Fawole et al.Laparoscopy visual evidence without histological confirmation). The overall 
Table 5. Summary of the details of the studies (Authors, year of study, setting/country, population studied, intervention, and methodology and outcome measure.

\begin{tabular}{|c|c|c|c|c|c|}
\hline Author & $\begin{array}{l}\text { Period of } \\
\text { study }\end{array}$ & Setting/Country & Population/Sample & Methodology & Outcome-Prevalence \\
\hline Ekwempu CC & 1978 & $\begin{array}{l}\text { Ahmadu Bello University } \\
\text { Hospital, Nigeria }\end{array}$ & $\begin{array}{c}329 \\
\text { Africans }\end{array}$ & Retrospective & $\begin{array}{c}27 / 329=8.2 \% \text { of histological confirmed } \\
\text { specimen after laparotomy }\end{array}$ \\
\hline Osefo NJ & 1989 & $\begin{array}{l}\text { Enugu, University } \\
\text { Hospital, Nigeria }\end{array}$ & $\begin{array}{c}1385 \\
\text { Africans }\end{array}$ & Retrospective & $\begin{array}{c}65 / 5995=4.3 \% \text { of histological confirmed } \\
\text { specimen after laparotomy }\end{array}$ \\
\hline Somigliana & 2012 & Uganda & $\begin{array}{c}351 \\
\text { Africans }\end{array}$ & Prospective & $\begin{array}{c}1 / 351=0.003 \% \text { Based on medical history and } \\
\text { clinical findings }\end{array}$ \\
\hline Fawole. A. O & 2015 & Ibadan Hospital, Nigeria. & $\begin{array}{c}239 \\
\text { Africans }\end{array}$ & Prospective & $\begin{array}{l}115 / 239=48.1 \% \text { Laparoscopy visual evidence of } \\
\text { endometriosis without histology confirmation }\end{array}$ \\
\hline
\end{tabular}

prevalence of endometriosis is indeterminable due to different study populations, methodology and diagnostic criteria.

\section{Discussion}

The systematic review was limited to studies documenting prevalence of endometriosis in Indigenous African as the primary outcome variable. The systematic review had limitations, Firstly; only a restricted number of articles met the inclusion of criteria $(n=4)$. Secondly, only one study had laparoscopic visualization of endometriosis as the diagnostic tool for endometriosis. Thirdly, in 2 of the 4 studies (Ekwempu et al. 1978 [2], Osefo et al. 1989 [1]), the data was collected retrospectively. Retrospective studies are prone to positive selection bias because of the risk of selecting the interesting cases, resulting in overestimation of the prevalence. Fourthly, taking different study populations, endometriosis diagnostic criteria and restricted number of articles that met the criteria, it was difficult to perform validated statistics

Only one study (Fawole et al. [3]) had laparoscopy as tool for visualization and diagnosis of endometriosis, but there was no histological confirmation of endometriosis. Visualization of endometriosis at surgery, mainly through laparoscopy, is still regarded as the Gold standard diagnostic test, confirming the existence of the lesion and has transformed its surgical treatment. [21] [22]. Better laparoscopic optics and video monitors, systematic evaluation of pelvic surfaces, and recognition of the variable appearance of endometriosis can improve the surgical detection of endometriosis, but the clinical appearance can mimic endosalpingiosis, cancer, or pelvic infection [23] [24] [25]. The positive predictive value, however, of a visual diagnosis may be as low as $45 \%$ [29]. The clinical diagnosis at surgery has important false-positive and false-negatives [26]. Laparoscopic visualization alone is likely to have positive bias especially with a hypothesis, endometriosis is more prevalent among African than earlier thought. It is therefore important to confirm the diagnosis of endometriosis by examination of biopsy samples stained with hematoxylin and eosin (H\&E). Overall, this reflects 
the limitations of this study. Histologically confirmation of endometriosis was only documented in 2 studies, Ekwempu et al. [2] 1978 - hysterectomy specimen and Osefo et al. 1989 [1] —Laparotomy specimen.

All studies did not have classification of the endometriosis. The type of endometriosis lesions observed were not described and the classification was not done in any of the studies. While Somigliana et al. 2012 [4], had a prospective and a recent study, the criteria of the diagnosis of endometriosis was through clinical history, clinical finding and investigations. Somigliana et al. 2012 [4], neither had any surgical nor histological confirmation of endometriosis.

Only one study (Fawole et al. [3] evaluated the correlation between endometriosis and the symptomatology (Chronic pelvic pain, Dyspareunia, Dysmenorrhea, Infertility). Their findings were women with endometriosis more commonly reported dysmenorrhea and pelvic pain. Both Osefo et al. [1] and Ekwempu et al. [2] combined both endometriosis and adenomyosis as one clinical entity in their reporting of prevalence of endometriosis; therefore, leading to reporting of higher prevalence of endometriosis. There was further limitation to Ekwempu et al. [2] study as, he only reported on histological specimen of the uterus after hysterectomy. The studies by Ekwempu et al. 1978 [2], Osefo et al. 1989 [1], were performed over 25 years ago when recognition of subtle endometriotic lesions were limited and could have resulted in underestimation of endometriosis. The lower experience of endometriosis among the Gynecologists could lead to increase or decrease recognition and prevalence of endometriosis.

There are hardly any well-designed analytical epidemiological studies of endometriosis among the indigenous Africans, this may be explained by the perception that endometriosis is infrequent among the Africans. The lifestyle and the social economic status of the Indigenous-African is changing, leading to late marriage and fewer children. This, exposes the African to long duration of uninterrupted menstruation with retrograde menstruation and therefore, increasing the risk of endometriosis [27] [28]). The earlier school of thought that endometriosis does not exist in African may not hold water. Lack of awareness of endometriosis as a potentially healthy problem among indigenous Africans and poor access to the gold standard for diagnosis of this disease, the laparoscopy, may contribute to this meager epidemiological data encountered in this study. The significance of racial factor is probably limited, since the prevalence of endometriosis appears to be higher in African American than indigenous Africans. Diagnostic challenges - limited training to gynecologists and lack of diagnostic and therapeutic (laparoscopic) facilities may be a contributory factor to this limited data to endometriosis. Due to the above factors, it was not possible to have pooled prevalence of endometriosis.

\section{Conclusion}

The articles analyzed cannot conclusively state the prevalence of endometriosis among the indigenous Africans. There is a research gap in endometriosis among 
the indigenous Africans. One area where research of endometriosis still needs to improve is the study of this disease in Indigenous African woman. Further prospective studies based on laparoscopic visualization and histological confirmation, are warranted to define more clearly the prevalence and clinical presentation of endometriosis among indigenous Africans. There is need to develop integrated and multidisciplinary endometriosis research programs in Africa.

\section{Financial Disclosure}

The authors have no relevant financial interests and no conflict of interest.

\section{References}

[1] Osefo, N.J. and Okeke, B.C. (1989) Endometriosis: Incidence among the Igbos in Nigeria. International Journal of Gynecology \& Obstetrics, 30, 349-353.

[2] Ekwempu, C.C. and Harrison, K.K. (1979) Endometriosis among the Hausa/Fulani Population of Nigeria. Tropical and Geographical Medicine, 31, 201-205.

[3] Fawole, A.O., Bello, F.A., Ogubonde, O., OduKogbe, A.O., Nkwocha, G.C., Nnoham, K.E., Zondervan, K.T., Akintan, A., Abdus-Salam, R.A. and Okunlola, M.A. (2015) Endometriosis and Associated Symptoms among Nigerian Women. International Journal of Gynecology \& Obstetrics, 130, 190-194.

[4] Somigliana, E., Vigano, P., Benaglia Crovetto, F., Vercellini, P. and Fedele, L. (2012) Endometriosis in Rural Setting: A Cross-Sectional Study. Gynecological Endocrinology, 28, 979-982.

[5] Ozkan, S., Murk, W. and Arici, A. (2008) Endometriosis and Infertility: Epidemiology and Evidence Based Treatments. Annals of the New York Academy of Sciences 1127, 92-100. https://doi.org/10.1196/annals.1434.007

[6] Eskenazi, B. and Warner, M.L. (1997) Epidemiology of Endometriosis. Obstetrics \& Gynecology Clinics of North America, 24, 2.

[7] De Graaff, A.A., D’Hooghe, T.M., Dunselman, G.A.J., Dirksen, C.D., Hummolshej, L. and Simoens, S. (2013) The Significant Effect of Endometriosis on Physical, Mental and Social Wellbeing: Results from an International Cross-Sectional Survey. Human Reproduction, 1-9. https://doi.org/10.1093/humrep/det284

[8] Nnoaham, K.E., Humnelshos, L., Webster, P., D’Hooghe, T., Nardone, F.C., Nardone, C.C., Jenkinson, C., Kennedy, S.H. and Zondervan, K.T. (2011) Impact of Endometriosis on the Quality of Life and Work Productivity: A Multicentre Study across Ten Countries. Fertility and Sterility, 92, 366-373.

[9] Simoens, S., Dunselman, G.A.J. and Dirksen, G. (2012) The Burden of Endometriosis: Costs and Quality of Life of Women with Endometriosis and Treated in Referral Centres. Human Reproduction, 27, 1292-1299. https://doi.org/10.1093/humrep/des073

[10] Kyema, C.M., Mwenda, J.W., Machoki, J., Mihalya, A., Simsa, P., Chat, D.C. and D'Hooghe, T.M. (2007) Endometriosis in African Women. Women's Health, 3, 629-663. https://doi.org/10.2217/17455057.3.5.629

[11] Okunlola, M.A. and Adekunle, A.O. (2002) Isolated Umbilical Endometriosis-A Rare Finding. The African Journal of Medical Sciences, 31, 281-282.

[12] Arumugam, K. and Templeton, A.A. (1992) Endometriosis and Race. Australian and New Zealand Journal of Obstetrics and Gynaecology, 32, 164-165.

[13] Shade, G.H., Lane, M. and Diamond, M.P. (2012) Endometriosis in the African- 
American Woman-Racially, a Different Entity? Gynecological Surgery, 9, 59-62. https://doi.org/10.1007/s10397-011-0685-5

[14] Chatman, D. (1976) Endometriosis and the Black Woman. American Journal of Obstetrics \& Gynecology, 125, 987-989.

[15] Sinaii, N., Cleary, S.D., Ballweg, M.L., Nieman, L.K. and Stratoon, P. (2002) High Rates of Autoimmune Disease and Autoimmune and Endocrine Disorders, Fibromyalgia, Chronic Fatigue Syndrome Atopic Diseases among Women with Endometriosis: A Survey Analysis. Human Reproduction, 17, 2715-2724. https://doi.org/10.1093/humrep/17.10.2715

[16] Veiga-Ferreua, M.M., Leiman, G., Dunbar, F. and Magolius, K.A. (1987) Cervical Endometriosis: Facilitated Diagnosis by Fine Needle Aspiration Cytogenic Testing. American Journal of Obstetrics \& Gynecology, 4, 849-856.

[17] Spitzer, M. and Benjamin, F. (1995) Ascites Due to Endometriosis. Obstetrical \& Gynecological Survey, 50, 628-631. https://doi.org/10.1097/00006254-199508000-00024

[18] Reiner, A.P., Carlson, C.S., Ziv, E., Iribarren, C., Jaquish, C.E. and Nickerson, D.A. (2007) Genetic Ancestry, Population Sub-Structure, and Cardiovascular DiseaseRelated Traits among African-American Participants in the CARDIA Study. $\mathrm{Hu}$ man Genetics, 12, 565-575. https://doi.org/10.1007/s00439-007-0350-2

[19] Lloyd, F.P. (1964) Endometriosis in the Negro Woman. American Journal of Obstetrics \& Gynecology, 89, 468-469.

[20] Janssen, E.B., Rijkers, A.C.M., Hoppenbrouwers, K. and D’Hooghe, M. (2013) Prevalence of Endometriosis Diagnosed by Laparoscopy in Adolescents with Dysmenorrhoea or Chronic Pelvic Pain: A Systematic Review. Human Reproduction, 19, 570-582. https://doi.org/10.1093/humupd/dmt016

[21] American Society for Reproductive Medicine (ASRM) (2006) Revised American Society for Reproductive Medicine Classification of Endometriosis. Fertility and Sterility, 67, 817-821.

[22] Harkki, P., Tiitnen, A. and Ylikorkala, O. (2010) Endometriosis and Assisted Reproduction Techniques. Annals of the New York Academy of Sciences, 1205, $207-$ 213. https://doi.org/10.1111/j.1749-6632.2010.05656.x

[23] Martin, D.C., Khare, V.K. and Parker, L.S. (1994) Clear and Opaque Vesicles: Endometriosis, Psammoma Bodies, Endosalpingiosis or Cancer? Journal of the American Association of Gynecologic Laparoscopists, 1, 21.

[24] Keltz, M.D., Kliman, H.J., Arici, A.M. and Olive, D.L. (1995) Endosalpingiosis Found at Laparoscopy for Peolvic Pain. Fertility and Sterility, 65, 482-485.

[25] Hesseling, M.H. and De Wilde, R.L. (2000) Endosalpingiosis in Laparoscopy. Journal of the American Association of Gynecologic Laparoscopists, 7, 215-219.

[26] Potlog-Nahari, Feldman, A.L., Sratton, P., Koziol, D.E., Segars, J., Merino, M.J. and Nieman, L.K. (2004) CD 10 Immunohistochemical Staining Enhances the Histological Detection of Endometriosis. Fertility and Sterility, 82, 1.

[27] Simpson, J. (1927) Peritoneal Endometriosis Due to Menstrual Dissemination of Endometrial Tissue into the Peritoneal Cavity. American Journal of Obstetrics \& Gynecology, 14, 422-469.

[28] D’Hooghe, T.M., Debrock, S., Hill, J.A. and Meuleman, C. (2003) Endometriosis and Sub-Fertility: Is the Relationship Resolved? Seminars in Reproductive Medicine, 21, 243-254. https://doi.org/10.1055/s-2003-41330

[29] Walter, A.J., Hentz, J.G., Magtibay, P.M., Cornella, J.L. and Magrina, J.F. (2001) 
Endometriosis: Correlation between Histologic and Visual Findings at Laparoscopy. American Journal of Obstetrics \& Gynecology, 184, 1407-1413.

https://doi.org/10.1067/mob.2001.115747

Submit or recommend next manuscript to SCIRP and we will provide best service for you:

Accepting pre-submission inquiries through Email, Facebook, LinkedIn, Twitter, etc. A wide selection of journals (inclusive of 9 subjects, more than 200 journals)

Providing 24-hour high-quality service

User-friendly online submission system

Fair and swift peer-review system

Efficient typesetting and proofreading procedure

Display of the result of downloads and visits, as well as the number of cited articles

Maximum dissemination of your research work

Submit your manuscript at: http://papersubmission.scirp.org/

Or contact ojog@scirp.org 